\title{
Enquadramentos e representações sociais da violência urbana na imprensa da amazônia paraense
}

\author{
Sergio do Espirito Santo Ferreira Junior ${ }^{1}$
}

Alda Cristina Costa ${ }^{2}$

\begin{abstract}
Resumo: O objetivo deste artigo é compreender como a cobertura sobre violência urbana na Amazônia Paraense realiza dois movimentos de organização simbólica da experiência e realidade sociais, ou seja, o enquadramento e a produção de representações sociais sobre a violência. Pelas narrativas jornalísticas são realizados esses movimentos, assumindo uma forma específica: a de narrativa policial. Essas narrativas não têm o objetivo só de apresentar relatos sobre fenômenos e acontecimentos, antes, participam de uma relação mediada, em que os sentidos subjetivos e as formas reconhecidas como violência são projetadas e aderem aos conhecimentos já difundidos em sociedade.
\end{abstract}

Palavras-chave: Enquadramentos. Representações sociais. Violência. Mídia impressa. Amazônia Paraense.

Abstract: The purpose of this article is to understand how the coverage of urban violence in Pará in the Amazon performs two Symbolic organizational movements from the experience and social reality, that is, the framework and the production of social representations of violence. These movements are performed by the journalistic narratives, assuming a specific form: the police narrative. These narratives are not intended only to present accounts of the phenomena and its events, but rather, as part of a mediated relationship in which the subjective senses and forms recognized as violence are designed and adhered to, in conformity with the knowledge already widespread in society.

Keywords: Frameworks. Social representations. Violence. Print media. Amazon from Pará.

\section{Introdução}

A mídia brasileira apresenta uma profusão de narrativas e modelos midiáticos de violência que reproduz e potencializa representações segundo as quais a realidade das cidades é palco de uma violência cotidiana, onipresente, periférica, destrutiva, ameaçadora, incontrolável, dentre outras características. É fenômeno midiático que emerge juntamente com outros fenômenos sociais. Ao pensarmos a região da Amazônia ${ }^{3}$, marcadamente em seus

${ }^{1}$ Universidade Federal do Pará (UFPA). E-mail: esferreira.sergio@gmail.com.

${ }^{2}$ Universidade Federal do Pará (UFPA). E-mail: aldacristinacosta@gmail.com.

${ }^{3} \mathrm{~A}$ Amazônia como a conhecemos hoje não se trata de uma região existente de maneira não-arbitrária, antes é também uma construção política, do período da Ditadura Militar no Brasil. O território que compreende a Amazônia Legal (composto pelos estados brasileiros do Acre, Amapá, Amazonas, Pará, Rondônia, Roraima, Tocantins, Mato Grosso e parte do Maranhão) foi demarcado pela Superintendência do Desenvolvimento da Amazônia (SUDAM), em 1966, como estratégia para sobrepor territórios da União ao dos estados, de modo que o governo federal pudesse adquirir o controle sobre ele (Becker, 2001). Apesar disso, a ideia da Amazônia como região à parte, periférica e a ser explorada pelo resto do Brasil, já se vinha construindo desde os séculos XVIII e 
aspectos de Amazônia urbana, as problemáticas atreladas a essa profusão midiática são o crescimento da violência e o seu condicionamento social, histórico e institucional no Brasil e seus estados, contradições no processo de desenvolvimento dos centros urbanos, manutenção e agravo das desigualdades sociais, localização do Brasil nas rotas de tráfico internacional, ineficácia de efetiva implantação de políticas de segurança e gestão deficitária da segurança pública.

Relativamente à Amazônia Paraense ${ }^{4}$, a mídia da região é marcada pela concentração. Os principais grupos do Estado do Pará são a família Barbalho, proprietária do jornal Diário do Pará, e a família Maiorana, dona do Amazônia Jornal e de O Liberal. Conforme afirma Castro (2012), esses grupos possuem padrões de estruturas de propriedade cruzada, em que é possível identificar a sua atuação áreas como jornalismo impresso, radiodifusão de imagem e som (televisão), radiodifusão de som (rádio), emissão por satélite e emissão por sinal pago. Isso reforça as tendências de um industrialismo midiático da violência, em que esses jornais apresentam a violência como criminalidade, como sinal do descontrole do Estado.

As narrativas desses meios priorizam a exposição pontual de ocorrências criminosas ou violentas, afastando-se de qualquer debate sobre o tema e ignorando completamente outras formas de violência, como por exemplo, as violações aos direitos humanos, violência dos conflitos agrários ou mesmo violência de gênero. Além disso, a própria ação da mídia, por meio da exposição de cadáveres, a desumanização de mortos e de pessoas envolvidas em crimes, acaba engendrando e reiterando violências simbólicas em relação, principalmente, às populações periféricas e às vítimas, alimentando a ideia de uma cultura do medo.

$\mathrm{Na}$ construção da presente reflexão sobre os sentidos subjetivos da violência nas narrativas, partimos dos tipos de crimes apresentados como a violência que povoa o cotidiano do estado brasileiro do Pará. A violência é reificada, mas também observamos uma série de representações sociais, em que as narrativas se alimentam e que são por elas difundidas no tecido social, na cotidianidade dos indivíduos dos espaços urbanos.

XIX, estatuto que os governos militares consolidaram com a sua política de expansão e ocupação daquela área. ${ }^{4}$ Situado na Região Norte do Brasil, o estado do Pará intercepta-se também com a Amazônia Legal, que é também identificada como Amazônia Brasileira. As representações a respeito da região, oscilam entre o exótico dócil e o fantástico selvagem, remontando ao processo de colonização e "domesticação" da região e dos nativos. A maneira como a Amazônia é perspectivada no contexto nacional e para além dele, conforme aponta Gonçalves (2005), abrange as ideias do vazio demográfico, segundo a qual a Amazônia seria uma grande área composta somente de fauna e flora, ignorando a existência de uma variedade de populações, desde as indígenas e ribeirinhas até as populações urbanas, além da ideia de que a região é uma provedora superabundante de recursos naturais para o resto do país e para o mundo. São todas perspectivas homogeneizadoras, que não dão conta do que seja a complexidade da região. Essa heterogeneidade se traduz em uma complexidade grande, mesmo de conflitos e vivências, como o mostra a realidade da violência urbana na região. 
Narrativas como forma simbólica não subsistem no vácuo. São formas culturais significantes social e historicamente estruturadas, fazendo parte de um campo-sujeito-objeto a ser interpretado, pois dão suportes a ideologias, elucidam aspectos de estrutura social e relações de poder, e fazem circular significações para além de um contexto de produção dessas formas culturais. (THOMPSON, 1998).

Em face dessa complexidade, nosso questionamento se volta para a violência como fenômeno subjetivo, em que pensamos essa organização da realidade no nível do enquadramento, compreendido como esquema interpretativo, que estabelece definições de situação e dos acontecimentos, inscrevendo-as nas narrativas midiáticas (GOFFMAN, 2012; TUCHMAN, 2002; MOUILLAUD, 2002), e no nível das representações sociais, como formas de conhecimento socialmente partilhada, organizadora de condutas, principal forjadora da subjetividade social, que condicionam as nossas percepções dos fenômenos e dos acontecimentos, em que o pensamento se constitui como uma atmosfera social e cultural (MOSCOVICI, 2011; JODELET, 2001).

Assim, nesta escrita, pensamos a narrativa dentro de um circuito simbólico e de subjetividade social, que abrange elementos percebidos nela e a partir dela, em um debate em que pretendemos compreender algumas das repercussões simbólicas oriundas desse 'industrialismo da violência', desse modus operandi midiático que se consolida no Brasil, em contextos local e nacional. Para os fins deste estudo, tomamos como análise os resultados da primeira etapa de investigações do Projeto de Pesquisa "Mídia e Violência: as narrativas midiáticas na Amazônia paraense" 5 (UFPA/CNPq), em que foram mapeadas 730 edições dos jornais Diário do Pará e O Liberal, do ano de 2012; e mais 360 edições do jornal Amazônia, ano 2013. Dessas descrições, analisamos os elementos sobre violência construídos nas narrativas policiais.

\section{Experiência, enquadramentos e representações sociais}

Em sua reflexão sobre a violência, Michaud (1989) alerta-nos sobre as profundas alterações que a ação da mídia insere nas relações dos indivíduos com a violência enquanto fenômeno. Em sua perspectiva, a partir da difusão midiática de imagens de violências

${ }^{5} \mathrm{O}$ projeto de pesquisa "Mídia e Violência: as narrativas midiáticas na Amazônia Paraense" está sendo desenvolvido desde 2012, na Faculdade de Comunicação, Universidade Federal do Pará, em parceria com o Conselho Nacional de Desenvolvimento Científico e Tecnológico (CNPq). O projeto foi dividido em três etapas: a primeira, análise dos jornais impressos paraenses; segunda, os programas televisivos de linha editorial policial e, terceiro, as mídias sociais Facebook e Twitter. 
espetaculares, sangrentas e atrozes, os sentidos subjetivos da violência, justamente as suas representações, frequentemente fazem como que nos deparemos com uma nova experiência, em que a realidade narrada pela mídia passa a integrar a experiência dos sujeitos.

Para Michaud, por causa das representações "não são tanto as violências efetivas que contam, mas sim o que delas ficamos sabendo e imaginamos. [...] $\mathrm{O}$ que conta não é a realidade vivida, mas o que ficamos sabendo o que a mídia deixa ver.” (MICHAUD, 1989, p. 49). Esse processo, na sua perspectiva, redunda em distorções e deslocamentos em relação à violência, bem como em banalização, à medida que as "imagens de violência contribuem de modo não desprezível para mostrá-la como mais normal, menos terrível do que ela é, em suma: banal. Cria-se assim um hiato entre experiência anestesiada e as provas da realidade". (MICHAUD, 1989, p. 49).

Essas identificações nos fornecem algumas pistas para pensar o uso midiático da violência, mas também a sua inserção em um ambiente que social e histórico, em que essa subjetividade se nos apresenta como modo de conceber o tipo de processo que se opera entre mídia, narrativas, representações e os indivíduos. Voltando à discussão sobre formas simbólicas, cumpre destacar que, como são formas culturalmente significantes, possuem significações para os indivíduos, que as produzem e as recepcionam a partir dos códigos e das convenções da cultura em que se situam e não estão dissociadas da realidade social, pois que se originam e circulam em contextos sociais específicos, o que significa que cumpre ter-se em conta as formas simbólicas e as modalidades de comunicação em que elas se inserem, como um fenômeno social contextualizado (THOMPSON, 1998).

Nesse sentido, compreendemos as narrativas midiáticas sobre violência dentro de um processo de mediação, calcado na captação e na circulação de valores, símbolos e representações já existentes na realidade social, realimentando-os e atualizando-os.

Cumpre, portanto, observarmos, como Berger e Luckmann (2011), que os sentidos sobre a realidade da vida cotidiana forjam-se a partir desses processos de objetivação e subjetivação da realidade, que podem estar condicionados a contextos de co-presença, mas que podem transcender o "aqui e agora", por meio da linguagem, capaz de ordenar a experiência social e a realidade percebida, além de abarcar propósitos pragmáticos dos indivíduos engajados nas interações cotidianas, sendo marcados por intersubjetividade. Por mais que se distingam múltiplas realidades, para as quais possamos ser transportados, pelas quais possamos transitar, assinalam também que essa realidade da vida cotidiana "conserva 
sua situação mesmo quando estes 'transes' ocorrem [...] a linguagem comum de que disponho para a objetivação das minhas experiências funda-se na vida cotidiana e conserva-se sempre apontando para ela" (BERGER; LUCKMANN, 2011, p. 43).

Essa discussão sobre a realidade, não consiste em uma tentativa de denunciar um falseamento ou uma dissimulação midiática face à violência, mas de verificar de que modo se constituem as distorções e deslocamentos que as narrativas instauram, bem como de que maneira elas potencialmente se integram às experiências sociais, principalmente as partilhadas.

Assim, essas distorções constituem algo como uma "cultura do espetáculo", que não deixa de dialogar com a sociedade e de lhe fornecer experiência. O olhar aqui adotado consiste justamente em problematizar esse processo de reconstrução simbólica, decorrente dessa mediação, trabalho de interpretação da realidade social, postas em circulação pela mídia. No diálogo com Thompson (1998), concordamos quando afirma que a mídia se constitui como instituição de poder simbólico, com a possibilidade de intervir, de modo mais sutil ou menos, nas ações e relações entre sujeitos e o seu contexto. No entanto, essa ação não pode ser vista em termos totalizantes, pelo contrário, ela não impede a elaboração das próprias experiências e rearranjos simbólicos na percepção da realidade.

Essas considerações sobre mídia e experiência nos levam ao percurso simbólico que as narrativas compreendem. Falamos, assim, de dois movimentos de organização simbólica da experiência e realidade sociais, ou seja, o enquadramento e a produção de representações sociais sobre a violência. $\mathrm{O}$ primeiro realiza-se na construção das narrativas e o segundo se faz difundir a partir delas. A própria narrativa se constitui como atividade de organização simbólica de uma experiência social e cultural, conforme aponta Motta (2004). Portanto, a narrativa da violência se dá na confluência dos elementos contextuais e da experiência.

Do ponto de vista do enquadramento, algumas pistas são-nos fornecidas em perspectivas sobre mídia e sociedade. Tuchman (2002) define o enquadramento midiático como elemento que molda e define os acontecimentos e que faz com que a realidade se constitua como um fenômeno social compartilhado. Mouillaud (2002) o define nos termos de um captador de fragmentos-acontecimentos, funcionando como uma "moldura", de corte e focalização, em que "um corte porque separa um campo e aquilo que o envolve; uma focalização porque, interditando a hemorragia do sentido para além da moldura" (MOUILLAUD, 2002, p. 61). 
A perspectiva de Goffman (2012) nos é particularmente cara, pois parte dessa perspectiva da intersubjetividade e da organização da experiência, em que os enquadramentos são vistos pelas interações da experiência social (em que a vida cotidiana adquire relevância central), que consistiria em olhar para e analisar aquilo a que os indivíduos se atentam nesse cotidiano, bem como interpretam e constroem os sentidos, e que é determinante para a compreensão dos acontecimentos. O autor se afasta de uma preocupação fenomenológica, deslocando-a para o social. É um tipo de análise que deve começar pela resposta à pergunta com que os indivíduos se deparam, em suas interações (que não são entendidas apenas como "encontro face a face", mas que envolvem outros indivíduos e os contextos de desencaixe também): O que está acontecendo aqui? Pergunta essa que é respondida a partir da consideração de aspectos, como as referências acionadas, os papéis dos indivíduos envolvidos e os seus perfis cognitivos, por exemplo.

Deste modo, como princípios organizadores da experiência social, Goffman define os quadros ou enquadramentos como os elementos que organizam e governam os acontecimentos (sobretudo, os sociais) e que são utilizados na definição das situações. Nesse sentido, compreendemos a ação da mídia, que ao elaborar as narrativas sobre os acontecimentos, acionam um quadro de sentidos sobre a violência, enquanto fenômeno social que se difunde no tecido social, isola seus elementos, fazendo ver a realidade a partir e com os fatos enquadrados, definindo assim os acontecimentos, respondendo às perguntas, realizando o corte e focalização, por meio dessa janela, desse quadro, potencialmente invisibilizador e que mascara a realidade.

O que chega ao segundo movimento, na medida em que a ação da mídia dá a ver e constrói simbolicamente uma realidade enviesada, projetando mais sentidos subjetivos da violência, justamente as representações. Representações sociais, que na perspectiva de Moscovici (2011), forjam-se entre aparência e realidade, entre imagens (algo como imagens mentais) e os fenômenos. Destaca esse caráter compartilhado e subjetivo das representações sociais, que não são pensadas por um indivíduo unicamente, antes estão em circulação pelo pensamento dos indivíduos, na "sociedade pensante". Essas representações ordenam as nossas perspectivas sobre a vida cotidiana, no jogo de visibilidade e invisibilidade social, estabelecidas pela fragmentação e classificação da realidade, das coisas e dos eventos, bem como na passagem da aparência das imagens à realidade e no compartilhamento de definições comuns aos membros de uma comunidade ou sociedade. 
Portanto, escreve Moscovici, as "representações que tanto nos orientam em direção ao que é visível, como àquilo a que nós temos que responder; ou que relacionam a aparência à realidade; ou de novo àquilo que define essa realidade" (MOSCOVICI, 2011, pp. 31-32).

Essa realidade compreendida como objeto social diante do qual se elaboram as representações, que servem como base de ação, definição e interpretação dele e nele. Ou, então, no envolvimento dos sujeitos, conforme aponta Jodelet.

Frente a esse mundo de objetos, pessoas, acontecimentos ou ideias, não somos (apenas) automatismos, nem estamos isolados num vazio social: partilhamos esse mundo com os outros, que nos servem de apoio, às vezes de forma convergente, outras pelo conflito, para compreendê-lo, administrá-lo e enfrentá-lo. Eis porque as representações são sociais e tão importantes na vida cotidiana. Elas nos guiam no modo de nomear e definir conjuntamente os diferentes aspectos da realidade diária, no modo de interpretar esses aspectos, tomar decisões e, eventualmente, posicionarse frente a eles de forma defensiva. (JODELET, 2011, p. 13).

Ou seja, como fenômeno social partilhado, erige-se sobre uma complexidade entre o subjetivo e o objetivo (ou objetivado). Desse modo, a violência do ponto de vista das representações sociais, trata-se de conceitos e ideias já circulantes no tecido social e que conformam as nossas relações, os modos de estar nos espaços, os conhecimentos que acionamos para perceber e reconhecer os elementos factivos da vida cotidiana. Instaura e organiza interpretações e ações sociais. Com essa perspectiva, a ação da mídia será instaurada, como um circuito simbólico.

\section{A rotinização dos deslocamentos}

Nesse processo, cumpre compreendermos o percurso de cada um dos impressos. O Diário do Pará foi fundado em 1982, pelo jornalista Laércio Barbalho, como meio de suporte da candidatura do sobrinho, Jader Barbalho, ao governo do estado do Pará, apresentando-o como combativo ao ideário da ditadura. Em 2000, o seu caráter de panfletário é redelineado, passando a ser um jornal menos declaradamente político do que então. A partir de 2003, passa a publicar um caderno de polícia, com notícias sobre homicídios, prisões por tráfico, ação da polícia, com manchetes agressivas e irônicas, e um caráter de popularesco, tal como a imprensa sensacionalista que se proliferou no Brasil, nas décadas de 80 e 90.

Os outros dois jornais, O Liberal e Amazônia Jornal, surgem, respectivamente, em 1966, com o apoio da ditadura militar, e em 2000, para alcançar o público do Diário, com a linguagem do popularesco e editorias de polícia, violência e televisão. Os três jornais usam da violência como meio de construção da imagem dos governos estaduais, mormente do Partido 
da Social Democracia Brasileira (PSDB), no poder desde a década de 1990. O Diário apresenta a violência com o apelo para consumo, mas também como meio de assinalar o descontrole e a ineficácia da gestão pública de segurança. Os outros dois jornais também usam a violência como meio atração ao consumo, mas também trazem um tom ameno sobre o governo, divulgando ações e políticas de segurança dos governos do PSDB.

É importante destacarmos que nas pesquisas sobre mídia e violência, as imagens de violência e as narrativas midiáticas não são espelhos do fenômeno social, assim como não podemos inferir que são falseamento da realidade. São construções e representações acionadas no repertório dos sujeitos sobre a violência. Ou seja, um fenômeno construído ou representado que aciona os aspectos do fenômeno e que enviesa a realidade. Algo como uma distorção, um deslocamento, que por meio desse procedimento, instaura maneiras específicas de se compreender a realidade. $\mathrm{Ou}$, narrativamente pela mídia.

\begin{abstract}
Os discursos sobre o mundo, inclusive as narrativas, são práticas discursivas de construção do mundo. $\mathrm{O}$ mundo físico e o mundo das relações sociais são o referente imprescindível para a criação de significados, mas a referencialidade é uma atribuição da linguagem, não do referente. Os indivíduos não experimentam suas condições sociais de existência, mas as constituem significativamente. A experiência não é fruto do impacto da realidade sobre a subjetividade, mas resultado da apreensão discursiva da realidade. As experiências por si mesmas, não prescrevem condutas, só o fazem ao ser consideradas, dotadas ou privadas de relevância (MOTTA, 2004, p. 15).
\end{abstract}

Nessa teia significativa, os sentidos e representações fornecidos pela mídia não passam despercebidos. Pelo contrário, são os principais forjadores contemporâneos de conhecimento dos objetos sociais e das subjetividades em torno da realidade. Por isso, estudar mídia e violência constitui-se como desafio e necessidade, em face de um complexo contexto de emergência do fenômeno social da violência urbana, mas também da difusão das imagens cada vez mais despersonalizadas e banalizadas de uma violência cotidiana, iminente, brutal, que grassa em todos os contextos, que mina o tecido social e os espaços da cidade.

Por isso mesmo, as narrativas, ao mesmo tempo em que se constituem como estrutura de expressão, em que os acontecimentos são encadeados, que apresenta temporalidade, ações simbólicas de personagens, um pano de fundo social e cultural, orientações pragmáticas, também "traduz[em] o conhecimento objetivo e subjetivo do mundo (o conhecimento da natureza física, das relações humanas, das identidades, das personalidades, das crenças, dos valores, dos mitos, etc.) em relatos (telling)" (MOTTA, 2004, pp. 18-19). 
A rotinização dos deslocamentos a que nos referimos, opera por meio desses procedimentos simbólicos do enquadramento e da representação social, percebido, com nuances, gradações e especificidades, em todos os impressos pesquisados pelo projeto de pesquisa.

Toda essa rotinização possui um pano de fundo da estruturação midiática na região e de como a violência urbana se tem delineado enquanto fenômeno. Os principais impressos da região, analisados pelo projeto, Diário do Pará, da Rede Brasil Amazônia de Comunicação (RBA), pertencente à família Barbalho, e O Liberal e o Amazônia Jornal, das Organizações Rômulo Maiorana (ORM), pertencentes à família Maiorana. O recorte toma o caderno de polícia como espaço privilegiado dessas narrativas diárias sobre a violência cotidiana que, segundo as construções desses impressos, espraia-se a partir de lugares muito bem definidos, as regiões periféricas da cidade.

No decorrer da pesquisa, constatamos que os deslocamentos se operam pela repetição exaustiva das ocorrências enquadradas como similares, com construções narrativas similares, nos termos de uma homogeneização dos fenômenos sociais, consiste justamente em uma prática de

\footnotetext{
afirmar que há um crescimento violência e a busca por atestá-lo com uma grande quantidade de registros e reiterar que a morte na periferia passa a fazer parte do cotidiano, do comum, porque os indivíduos dessas regiões estejam envolvidos direta ou indiretamente com as ordens do crime e do tráfico (FERREIRA JUNIOR; MENEZES, 2014, p. 68).
}

Há algumas nuances, como dito, nessas rotinas narrativas. Podemos descrevê-las como a presença de pouco texto, o uso mais frequente e evidente de manchetes agressivas, chulas e desrespeitosas, bem como de imagens fotográficas com marcas de violência (como sangue, cadáveres, ferimentos, destroços) pelo impresso Diário do Pará. A presença de bastante texto e o uso mais ameno da fotografia, com marcas de violência mais atenuadas, por O Liberal. E a presença também de pouco texto e fotografias mais dramatizadas no Amazônia Jornal. No entanto, trata-se mesmo de uma rotina narrativa, logo, não se furtam a falar da violência dos termos do deslocamento.

Os dados analisados referem-se justamente a alguns elementos bastante pontuais e presentes no cotidiano que a página do jornal contém e recorta. São os dados sobre os tipos de crime noticiados. Esses tipos de crime são importantes, porque a sua evidência não está somente inscrita nos textos, salta aos olhos nas fotos de capa e junto aos textos, completadas 
pelas manchetes chamativas. Os tipos de crimes são, nesse caso de cobertura, o principal elemento, que vai definir as construções narrativas e o tipo de conhecimento sobre a violência projetado pelas páginas dos jornais, conforme é possível verificar a partir dos gráficos abaixo.

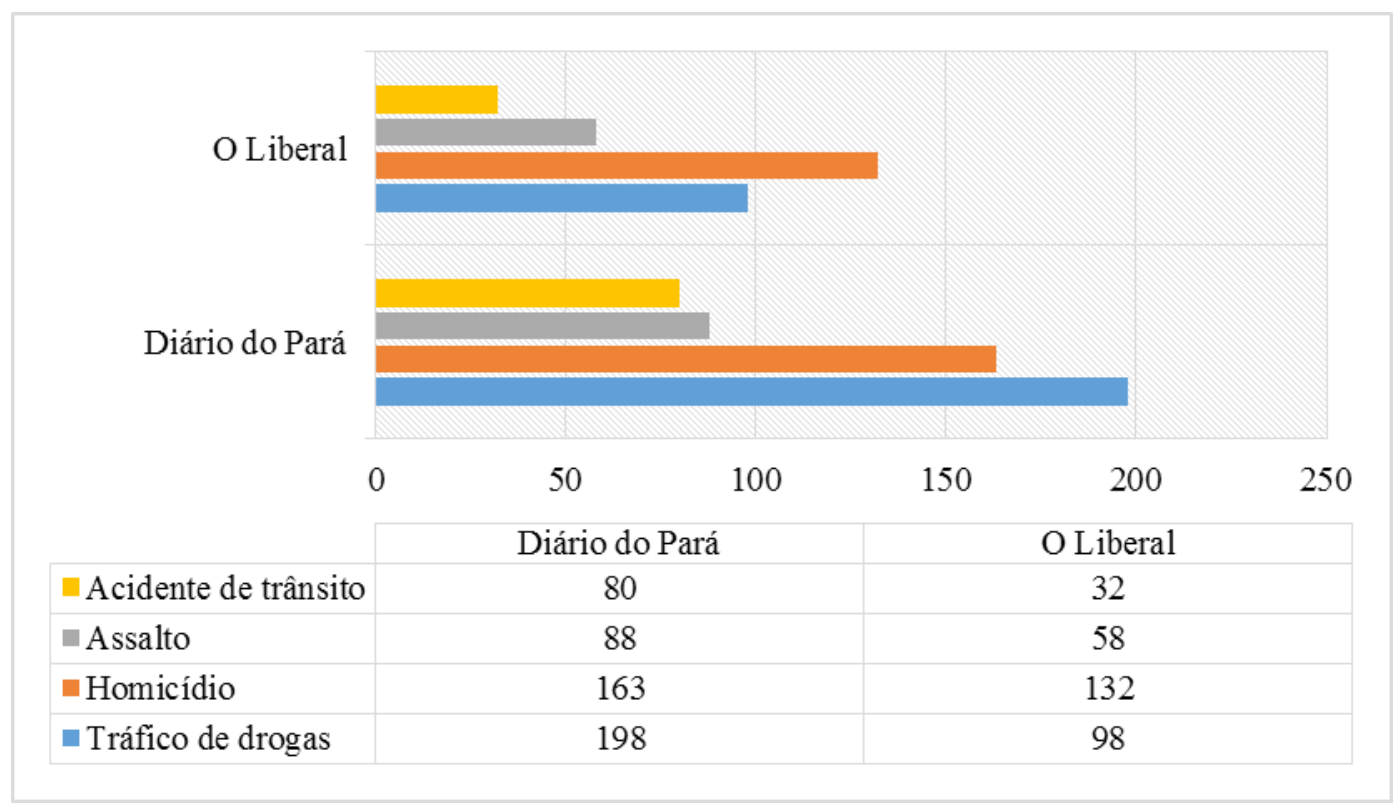

Figura 1: Tipo de crime registrados no Diário do Pará e O Liberal, mar./mai. 2012. Fonte: Diário do Pará/O Liberal

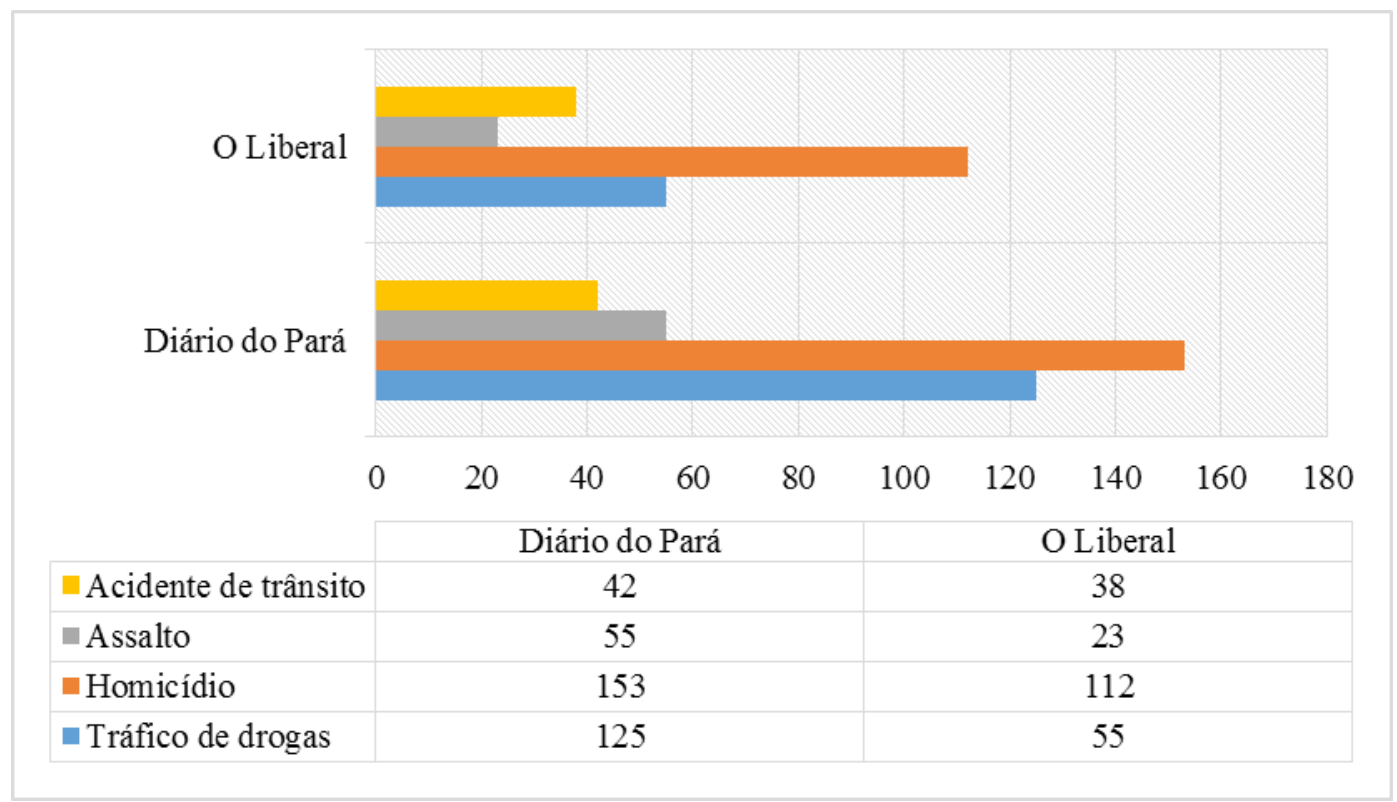

Figura 2: Tipo de crime registrados no Diário do Pará e O Liberal, ago./out. 2012. Fonte: Diário do Pará/O Liberal

No Diário e em O Liberal, no período analisado pelo projeto, os tipos de crime mais noticiados são os listados acima, com um grande registro para homicídios, prisões por tráfico 
de drogas e casos de assalto, tanto prisões quando denúncias. Exceto pelos acidentes, todos os outros, constituem-se e são enquadrados do ponto de vista do crime e da criminalidade. A diferença quantitativa entre os impressos nos registros dos casos exprime-se no espaço destinado a cada um na cobertura de violência. O Diário do Pará possui um caderno, com 8 a 12 páginas, em que se misturam um número expressivo de fatos. Observamos que além do grotesco construído e os crimes com requintes violentos, o periódico valoriza nas suas páginas a quantidade de crimes. O número tem um significado importante, pois reforça o crescimento da violência e a incompetência do Estado em gerir a política de segurança pública.

O Liberal, em sua editoria de Polícia, do mesmo tamanho do resto do jornal, apresenta entre 4 a 6 páginas, que dividem espaço com notícias de outro caráter, como internacional e outros assuntos atrelados à segurança, que não somente eventos violentos.

Desses registros, os casos de homicídio, de tráfico e assalto são os que mais se projetam e dão a ver o caráter e configuração da violência urbana apresentada nos jornais, em ambos os casos. O homicídio abarca categorias narrativas do jornal como o próprio homicídio, assassinato e execução, que descreveremos melhor a seguir. No caso das prisões por tráfico, a maior parte dos casos é da prisão de pequenos traficantes, havendo também uma parcela de grandes apreensões. Nos casos de assaltos, o principal elemento é o acusado, que é apresentado como alguém advindo de ou agindo em regiões de periferia. A presença dos acusados, como origem da violência e encarnação de tipos estereotípicos, é dos principais elementos narrativos.

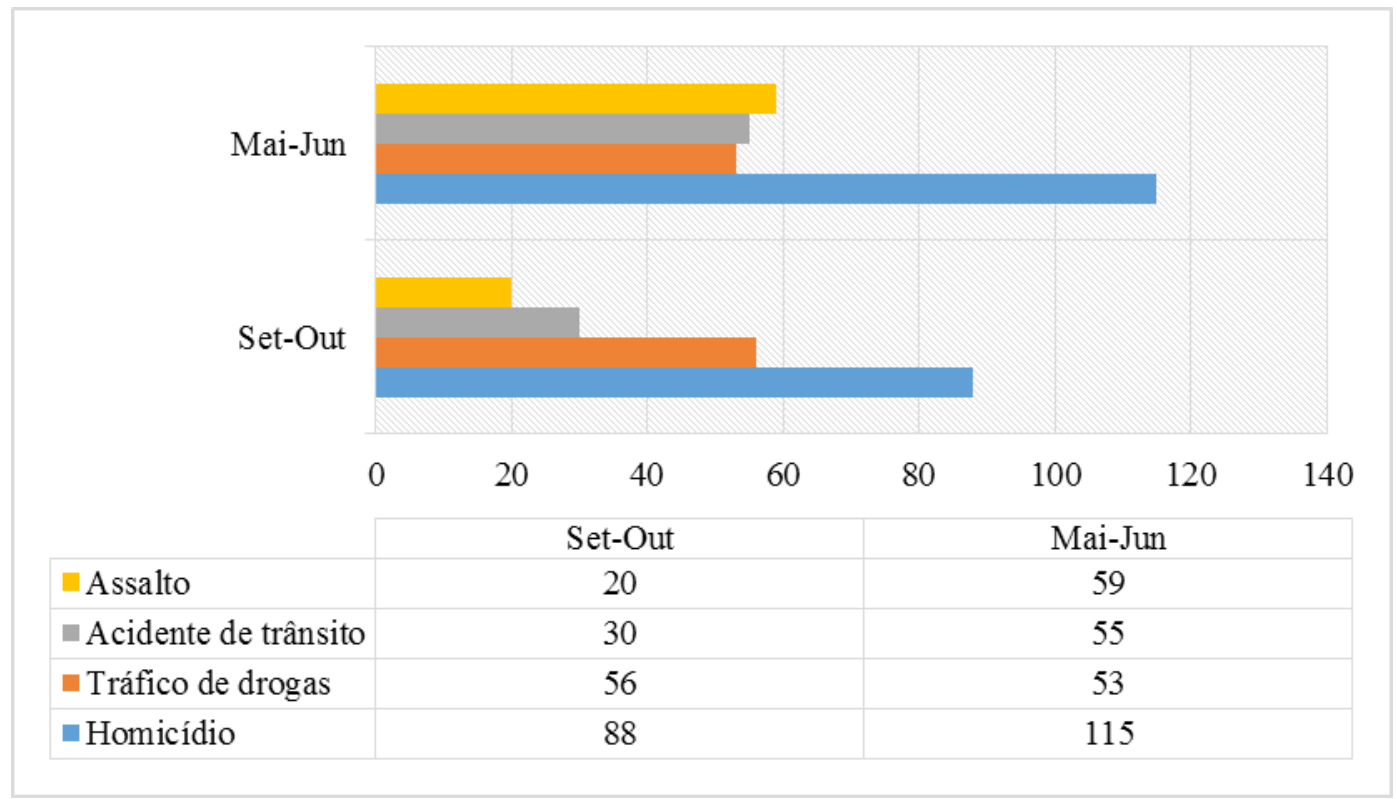


Figura 3: Tipos de crimes registrados no Amazônia Jornal, mai./jun. e set./out. 2013.

Fonte: Amazônia Jornal/Elaborado pelos pesquisadores

No caso do jornal Amazônia, analisado em outro período, já em 2013, apresenta semelhanças com o Diário do Pará, especificamente na questão da construção da narrativa grotesca. O jornal não possui editorias independentes, apresenta-se em formato revista. Tem em média 48 páginas e passa de um assunto ao outro sem separações. O Amazônia utiliza a contracapa como capa principal de assuntos de violência.

A cobertura jornalística fica entre homicídios e tráfico de drogas. Mesmo sendo um número menor de meses, os dados se aproximam muito dos indicados em outros impressos. Os mesmos modos de narrar se operam também neste impresso. A rotina narrativa desses impressos, de 2012 e 2013, mesmo hoje, segue inalterada, repete-se, recusa-se a ir além dos lugares comuns do crime e da criminalidade, da evidenciação dos desviantes e dos perigosos indivíduos, da apresentação do combate à violência como o policiamento somente. Dá-nos a ver enviezadamente o fenômeno, mas nos fala muito sobre os sentidos da violência projetados ali e além. O que nos leva, então, aos movimentos simbólicos.

\section{Os enquadramentos}

A coincidência com a categoria jurídica do crime ou com a categoria dos acontecimentos não é um dado gratuito. É imprescindível ao modus operandi dessas narrativas de violência. Funciona como a porta de entrada, a janela pela qual se vê o desenrolar dos eventos da narrativa. Motta (2004) afirma que na construção do mundo, realizada por meio de narrativas, a realidade se introduz nas práticas humanas por meio de categorias e descrições, em que "o mundo passa a existir na medida em que as pessoas falam, descrevem, relatam e discutem sobre ele, na medida que organização representações mentais sobre ele" (2004, p. 15).

Essa categorização opera-se pelo enquadramento, pelo acionamento dos quadros de sentido subjacentes às narrativas de violência. Conforme Goffman, esses enquadramentos são o meio que nos habilita a perceber e reconhecer os acontecimentos da vida cotidiana. São a articulação de vários esquemas interpretativos que, juntos, concorrem para definir o quadro. Do ponto de vista, do que chama de esquemas primários, considerados pelos que o aplicam, como inteligível em si mesmo, cuja interpretação na situação é feita de modo imediato, parecendo não depender de interpretações anteriores ou originais. Segundo o autor o esquema 
primário é aquele que "permite ao seu usuário localizar, perceber, identificar e etiquetar um número aparentemente infinito de ocorrências concretas" (2012, p. 45), de modo que confere significado a eventos ocorridos em determinados momento. Utilizar-se desses esquemas, de acordo com Goffman, é uma competência dos indivíduos em sociedade, que o fazem sem grandes dificuldades, uma vez já são condicionados social e historicamente a entender os acontecimentos a partir de determinados elementos que o constituem, a partir da experiência organizada.

Nesse modo de narrar da violência, portanto, o enquadramento é dado pelo tipo de crime, principalmente, que vai condicionar mesmo as valorações, a apresentação dos acontecimentos e das interpretações dos personagens sobre os acontecimentos. E a estruturação da narrativa se dará na similaridade, obedecendo à lógica de organização que o enquadramento requer e que é adotada na rotina da narração da violência.

Para cada tipo de crime, quadros específicos e narrativas específicas. De modo que podemos descrever, a sucessão e transformação dos acontecimentos e desenrolar lógico e cronológico (Motta, 2004, p. 19) a partir desse movimento de enquadrar. Para os casos de tráfico de drogas, a narrativa apresenta a ação da polícia, quer de ronda, físcalização ou incursão às periferias, em que a polícia é o principal agente combativo dos crimes que ocorrem nos recônditos das periferias. A ação policial é definida em termos de prisão e apreensão de entorpecentes. À prisão dos acusados, segue-se obtenção de informações sobre a ação dos traficantes, apresentadas em depoimentos do próprio acusado ou em relato da polícia. Os personagens centrais são o acusado, inimigos da ordem, e os policiais, restauradores da ordem.

No caso dos homicídios, um quadro necessariamente mais complexo se delineia. Não só pela pluralidade dos acontecimentos, mas também pelos modos de narrar que vão assumir diferentes nuanças, recorrentes em todos os impressos. Constatamos assim, pelo menos duas tendências identificadas no decorrer da pesquisa, que também se utiliza de um maniqueísmo, como assinalado acima. Nos casos de homicídio, o fato de ocorrer um homicídio e o elemento ensejador do quadro, mas a ele mais um esquema interpretativo adere. $\mathrm{O}$ da natureza do morto, identificado em termos de bem ou mal, de bom ou mau, especificado nas narrativas. Os personagens são os mortos, os assassinos, as testemunhas, os parentes das vítimas, os policiais. A morte, sempre violenta, sempre brutal, é apresentada por dois vieses: o da morte inesperada do bom e o morte normalizada do mau. 
Cada uma possui uma estrutura e um pano de fundo narrativos. No primeiro caso, o indivíduo é alvo da violência onipresente e inevitável, que já dominou os espaços urbanos e se abate sobre trabalhadores, donas de casa, policiais, empresários, cuja inserção é da ordem do “cidadão de bem”, que não está "metido em vida errada". As ações são a morte, decorrente da violência dos indivíduos que encarnam os contrários a esses mortos, bem como o lamento de testemunhas e parentes. Do ponto de vista da morte normalizada do mau, é algo de caráter familiar aos contextos periféricos, fruto das sociabilidades violentas desses espaços, que se abate, aos indivíduos desviantes, moral e legalmente, definida como "acerto de contas", indicador somente do desalinho dos indivíduos e de que a morte é esperada para esses indivíduos. É um homicídio, mas a culpabilização oscila em torno da própria vítima, que por escolhas próprias se pôs no caminho cujo fimm é a morte, indicadora nas páginas dos jornais, da completa barbárie que se tornou a periferia.

Ainda que a leitura realizada pareça demasiado generalista, cremos ser suficiente ao objetivo empreendido e adequada ao procedimento homogeneizador realizado pelas narrativas midiáticas de violência, que inscreve nas narrativas sentidos subjetivos da violência muito específicos e restritos aos elementos narrativos acionados, como local, os personagens e a sucessão dos acontecimentos.

\section{As representações sociais}

Se no enquadramento, observamos o que está inscrito nas narrativas, com as representações destacamos os movimentos que se operam a partir narrativas abarcadas pelos termos acima. Necessariamente interpretativo, esse processo, no entanto, ajuda-nos a responder mais claramente o que percebemos ocorrer difusamente na sociedade, não só relativamente à sensação de insegurança e do caos urbano, mas ao que já está na sociedade, ao que volta para ela por meio das narrativas. Ou seja, ao circuito simbólico.

Em Moscovici (2011), as representações sociais são definidas enquanto fenômeno, a que subjazem alguns processos e potencialidades. Essas potencialidades em nossas análises são produzidas e difundidas pelas narrativas midiáticas de violência, assinalando sua repercussão no ambiente social e histórico em que estão inseridas. Essas características são, a partir da teoria do autor: convencionalização, ancoragem e objetivação.

Convencionalização e ancoragem atuam juntas. O primeiro processo refere-se à produção de convenções relativamente a objetos, pessoas e acontecimentos, em que as 
representações "lhes dão uma forma definitiva, as localizam em uma determinada categoria e gradualmente as colocam como um modelo de um determinado tipo, distinto e partilhado por um grupo de pessoas" (MOSCOVICI, 2011, p. 34). Fala em termos dos aspectos convencionais da realidade. De onde vem as ideias da cidade perigosa, de onde vem as sensações de insegurança em espaços periféricos, com marcas de pobreza e de precária urbanização? A mídia as difunde, em âmbito local e nacional. Mas essas representações também têm a ver com o pano de fundo da urbanização no país, que sempre foi marcada por oposições evidentes, entre centro urbanizado/civilizado/organizado e periferia precarizada/incivilizada/desorganizada, em que os espaços são pensados como mundos à parte um do outro, em que o segundo representa ameaça ao primeiro, ao seu conforto, à sua segurança.

Observamos assim, uma série de práticas que confirmam isso, como as investidas policiais marcadamente violentas nas periferias e as próprias narrativas midiáticas, que fazem circular esses aspectos convencionais da violência. Ao que se soma a ancoragem, processo que "transforma algo estranho e perturbador, que nos intriga, em nosso sistema particular de categorias e o compara com o paradigma de uma categoria que nós pensamos ser apropriada" (MOSCOVICI, 2011, p. 62). É um processo de classificação, de nomeação. O perturbador e ameaçador da violência visibilizado pelas categorias, como as descritas, acima, do acerto de contas ou da morte dos "cidadãos de bem", são representações ancoradas, algo próximas de uma rotulação dos indivíduos e dos acontecimentos. Novamente, falamos de um processo em que a narrativa midiática está inserida, mas não está circunscrito a ela. O conhecimento corrente na sociedade sobre as condutas e os ideais produtivos, faz com que a narrativa midiática se legitime e seja reconhecida.

Desse processo, redunda a objetivação, a integração à experiência, pois que essas representações se fossilizam, como afirma Moscovici. Elas se materializam, ou então:

A objetivação une a ideia da não familiaridade com a de realidade, torna-se a verdadeira essência da realidade. [...] Em outras palavras, tal autoridade está fundamentada na arte de transformar a representação em na realidade da representação; transformar a palavra que substitui a coisa, na coisa que substitui a palavra" (2011, p. 71).

Portanto, retornamos ao início desta escrita, às representações da violência, sobrepõem-se à vivência da violência. Um fenômeno subjetivo que é potencializado sobremaneira pela mídia, uma repercussão simbólica, que organiza práticas cotidianas, faz- 
nos mobilizar conhecimentos, em forma de incertezas, medos, inseguranças, ou certezas sobre a origem da violência, a sua iminência. Assim, percebemos um diálogo complexo, entre a representação social e a experiência social, de que as narrativas midiáticas participam na construção do pensamento dos sujeitos. A mídia forja uma experiência social que opera e organiza as representações de modo totalizante.

\section{Considerações finais}

Violências dramatizadas, violências invisíveis, violências enviesadas. Nesse modo de narrar o fenômeno da violência urbana no contexto da Amazônia Paraense, inscrevem-se processos sociais que definem os acontecimentos, definem os seus personagens, definem os sentidos subjetivos sobre essa violência. E passamos a ver a violência do crime e da criminalidade algo da ordem do comum, do cotidiano, agregando elementos dessas representações projetadas pelos enquadramentos e narrativas midiáticos, às nossas representações sociais.

O que se apresenta nesse circuito simbólico de representações da violência, é uma constante alimentação e realimentação em que a mídia paraense é, se não o principal, pelo menos um dos mais importantes agentes de dinamização, difusão, atualização. $O$ enviesado produzido pelas narrativas demonstra um uso dramatizado da violência, um uso social perverso, mas que não parte de um vácuo social, de sentidos inventados sobre violência, mas de percepções existentes nos sujeitos. Falamos de uma determinada experiência cultural e social, já sedimentada, de que a mídia se usa, com a qual ela dialoga.

O que não nos impede, no entanto, de questionar o caráter das narrativas e imagens midiáticas da violência, de pensar e repensar essas repercussões simbólicas e o tipo de contribuição que acarreta ou o tipo de negações que realiza. Falamos de uma rotina narrativa que urge por alterações. Mas também falamos de uma experiência à qual essas narrativas aderem, cujos elementos são reconhecidos nas narrativas.

É um ambiente de representações suficientemente complexo, para nos fazer pensar nas complexidades do fenômeno, do contexto político, social, histórico e cultural da sociedade brasileira. Um ambiente suficientemente complexo, em que tendências de invisibilização, de negações dos "outros" sociais, de esvaziamento dos direitos humanos, oferecem-se a nós como modo de conhecer e abarcar o mundo social, aquém e além das narrativas. 


\section{Referências bibliográficas}

BECKER, Bertha K. Revisão das políticas de ocupação da Amazônia: é possível identificar modelos para projetar cenários? Parcerias estratégicas, n. 12, 2001. p. 137-159.

BERGER, Peter L.; LUCKMANN, Thomas. A construção social da realidade: tratado da sociologia do conhecimento. 33. ed. Petrópolis: Vozes, 2011.

CASTRO, Fábio Fonseca de. Sistemas de Comunicação na Amazônia. Revista Fronteiras: estudos midiáticos, v. 14, n. 3, nov./dez. 2012. p. 179-191.

FERREIRA JUNIOR, Sergio; MENEZES, Alana. Individualização do acontecimento e mortes violentas: as narrativas policiais da mídia impressa paraense. Temática, João Pessoa, ano 10, n.11, nov. 2014. p. 55-70.

GOFFMAN, Erving. Quadros de experiência social: uma perspectiva de análise. Petrópolis: Vozes, 2012.

GONÇALVES, Carlos Walter Porto. Amazônia, Amazônias. São Paulo: Contexto, 2005.

JODELET, Denise. Representações sociais: um domínio em expansão. In: . (Org.). As representações sociais. Rio de Janeiro: Ed. UERJ, 2001. p. 17-44.

MICHAUD, Yves. A violência. São Paulo: Editora Ática, 1989.

MOSCOVICI, Serge. Representações sociais: investigações em psicologia social. 8. ed. Petrópolis: Vozes, 2011.

MOTTA, Luiz Gonzaga. Narratologia: análise da narrativa jornalística. Brasília: Casa das Musas, 2004.

MOUILLAUD, Maurice. A crítica do acontecimento ou o fato em questão. In: MOUILLAUD, Maurice; PORTO, Sérgio Dayrrel (Org.). O jornal: da forma ao sentido. 2. ed. Brasília: Editora Universidade de Brasília, 2002. p. 48-83.

THOMPSON, John B. A mídia e a modernidade: uma teoria social da mídia. Petrópolis: Vozes, 1998.

TUCHMAN, Gaye. As notícias como uma realidade construída. In: ESTEVES, João Pissarra. (Org.). Comunicação e sociedade: os efeitos sociais dos meios de comunicação de massa. Lisboa: Livros Horizonte, 2002. p. 91-104. 